\title{
Designing Model of Serious Game for Flood Safety Training
}

\author{
Nursyahida Mokhtar ${ }^{1}$, Amirah Ismail $^{2}$, Zurina Muda ${ }^{3}$ \\ Faculty of Information Science and Technology, \\ Universiti Kebangsaan Malaysia \\ 43600 Bangi Selangor, Malaysia
}

\begin{abstract}
Serious games have the potential to increase motivation among users in the aspect of safety training. Additionally, serious games can also positively impact training outcomes when the knowledge and skills acquired during a serious game training are transferred to a real-world application. The development of a serious game is based on the game elements and theories determined according to the goals or objectives of the game being developed. There are existing serious games that have been used for training but less usage of scenarios and feedback element render the game less effective for training purposes. Besides that, existing serious games for training purposes fail in delivering domain content to achieve the game objectives since they are more focused on entertainment. This is because the games do not involve experts in providing game domain content. The objective of this paper is to design a serious game model for flood safety training. Preliminary study and literature review are used in this study as the research method. The result of this study is a model of a serious game for flood safety training. In conclusion, this study focuses on the design of a serious game model for flood safety training that includes the elements of serious game identified and adapted to psychology readiness based on the flood training module by Malaysian Defense Force (APM). This makes the serious game more attractive and can give intrinsic motivation to players. For future studies, every single element serious game and theory of psychology readiness in the model developed in this study will be validated with the expert game and expert psychology.
\end{abstract}

Keywords-Serious game model; flood safety training; flood awareness; intrinsic motivation; psychology readiness

\section{INTRODUCTION}

The rapid growth of multimedia technologies over the last 20 years means that today's children and young adults were born in a computerized world and are used to handling all kinds of software products and games [1][2]. A serious game is one the multimedia technologies [3][4] defined as an interactive computer application with or without significant hardware components, that has a challenging goal, fun to play and engaging, incorporates some scoring mechanism, and supplies the user with skills, knowledge, or attitudes that are useful in reality.

One of the uses of serious games is for training purposes. The main purpose in a training context is to help players to reach their learning objectives and provide an alternative method of training to gain and maintain skills. Besides that, serious games for training aim to keep the interest in training activities high by keeping players entertained, yet interest and motivation often wane over games. There are many domains in which people need to invest their time and effort in a training activity to see future benefits. One of the instances where serious games have been used is in natural disaster training. Natural disaster is a phenomenon which occurs all around the world in various ways such as floods.

Floods are a natural disaster of concern to society as floods negatively impact humans and infrastructures [5]. When a flood occurs, besides physical readiness, psychological readiness is also important for monitoring and adjusting individual responses.

According to [6], the awareness level of civilians on the importance of preparing for floods is still low. This statement is supported by the APM. Although various methods have been conducted by APM to prepare the civilians physically or emotionally, they still do not show a positive response to do flood preparation. APM requires a more interactive medium of disseminating necessary information. This is because existing mediums such as flyer distribution, television advertisement, APM official social media and video on the official APM website do not give a positive impression to the civilians.

Therefore, serious games are suitable to disseminate information [7] and can be used as a medium for training because serious games allow users to experience situations that are difficult to achieve in reality due to factors such as cost, time and safety.

Serious games are already being used for training purposes in real-life [8]; however, they do not gain much popularity as less usage of scenario and feedback element are integrated into the games, making the games less effective for training. Therefore, serious games must be developed in such a way that it can show more than one scenario to generate feedbacks more often. Because the role of feedback in serious games for training is important as it can give intrinsic motivation to players to keep playing [9]. In addition, existing serious games fail to deliver domain content to achieve game objectives. But, are more focused on entertainment [10][11]. This happens because it does not involve expert in providing game domain content.

The objective of this study is to design a serious game model for flood safety training which has three flood situation scenarios equipped with elements and psychological readiness theory that can provide intrinsic motivation to players. Besides, this game also involves experts to provide game domain 
content. This serious game helps the APM to convey information on flood safety based on flood training modules to the civilians. Furthermore, this serious game can give the awareness to the civilians of the importance of preparing for flood situations.

A serious game for flood safety training focuses on training objectives in the context of games that resemble real-world scenarios. Players are briefed on the real flood situations to explain the actions that should be taken when floods indeed occur [12]. Therefore, the tasks in the game are designed according to the appropriateness of the flood training modules to help players adapt to the game environment. This study is divided into several sections including introduction, research method, research findings, design model, discussion, conclusions and future works.

\section{METHOD}

This qualitative research uses two research methods: i) Preliminary study involving interview session conducted at the Malaysia Civil Defence Force Training Academy (ALPHA) in Bangi, Selangor, with six members of APM to obtain data, and ii) literature review as shown in Fig. 1.

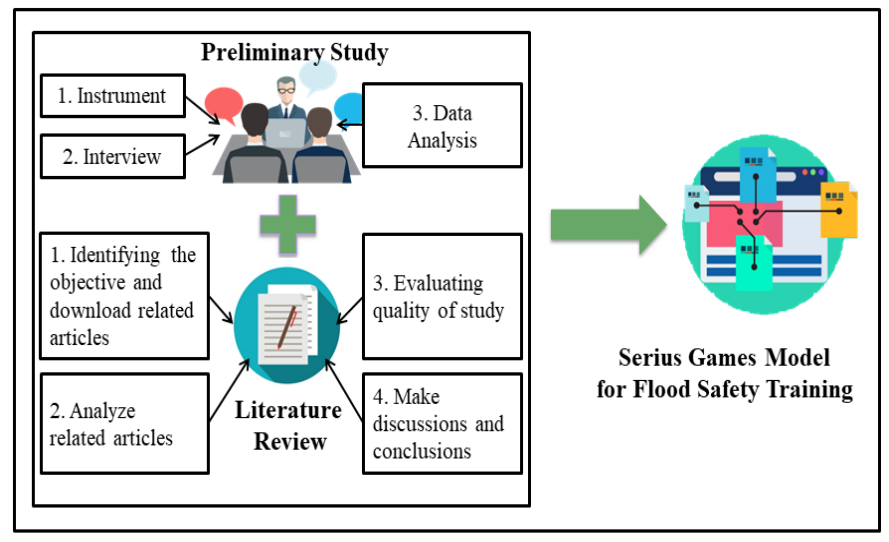

Fig. 1. Method for design a serious game model for flood safety training.

Preliminary study was conducted using the interview method to obtain data analysis of flood awareness training preparation among civilians, the existing methods of dissemination of flood awareness information and the need for technology requirements to carry out the flood awareness training preparation from the experts' perspective.

Literature review was conducted to identify the elements of a serious game for training in various domains used in previous studies and then to identify the appropriate elements that can provide intrinsic motivation to the players which can be applied into the serious game for flood safety training. Additionally, literature review was done to identify the suitable theories and approaches to be applied in flood preparedness training.

\section{A. Preliminary Study}

The preliminary study for this research has three phases. Phase 1 is setup to identify the objective of the preliminary study, preparation of the instrument, and to identify the informants. Phase 2 is data collection which was carried out by conducting interview sessions with the informants while Phase 3 is data analysis to analyse the information gathered from the interview. The content of the data analysis for the interview method has been discussed in the preliminary study of flood awareness training preparation using serious games [13].

\section{B. Literature Review}

The literature review method which is adapted from [14] has four phases. Phase 1 identifies the objectives of the literature review to retrieve articles relevant to this research. Phase 2 analyses the retrieved articles. Phase 3 determines the quality of the articles analysed by ensuring that articles are downloaded from reliable databases. Finally, Phase 4 discusses the findings before making conclusion.

1) Identifying the objectives and downloading related articles: In this phase, the primary purpose of literature review was identified to ensure the title and contents of the journal articles selection conform to the topic of research. The articles were selected based on two methods. In the first method, the articles were identified using the search of title, domain keywords, and abstract, where selected articles were from years 2009-2018.

The keywords used were "Serious Games", "Serious Game Training", "Disaster", "Flood", "Psychology Readiness" and "Intrinsic Motivation". The databases used for downloading articles were Google Scholar, IEEE Xplore, ACM Digital Library, and Science Direct.

The selected articles must be written in English. According to [15], the first search method involved articles focusing specifically on the title, known as the 'primary' articles. The second method involved articles that were not related to the title; thus, the search needed to be wider and known as the secondary source. For the secondary source, the article titles did not discuss the domain but there were related contents. The search was done with a quick reading of the content of the articles and then focused on the relevant contents.

Meanwhile, another approach used is called snowballing [16] (i.e. retrieving relevant papers based on target papers' references list or paper citing). Articles downloaded in the form of PDF files were structured in the Mendeley program to facilitate the arrangement of references. From the 100 related articles downloaded, 24 studies were related to the elements of serious game for training, one study was related to readiness psychology, and eight studies were related to intrinsic motivation.

2) Analysing related articles: The criteria and specifications of the downloaded articles were analysed. First, articles that stated the elements of game were selected. Next, the elements that can give intrinsic motivation to players were identified. Finally, articles related to the psychology readiness of the society related to flood are identified. According to [15], the critical aspects observed during the analysis of literature studies include definitions, objectives, characteristics, historical analysis, success factors, failure/problem factors, research methods, theory, further studies, and contents. 
3) Evaluating the quality of study: In this evaluation phase, articles that were not documented in detail are not selected. The selected articles must also be retrieved from a reliable database.

4) Discussions and making conclusions: The result of the review method is the elements of serious game for training, elements that were identified to provide intrinsic motivation to users, and psychology readiness. The detail result will be discussed further in the next section.

\section{RESULT}

In this section, the results are discussed details based on the findings from the preliminary study, literature review. Next, as a final result, result from both of these two methods is combined to produce a design model of serious game for flood safety training.

\section{A. Result Systematic Review}

The result of preliminary study has been discussed in the previous paper preliminary study of flood awareness training preparation using serious games [13].

Furthermore, APM advised that game need to be developed based on the APM flood safety training module to deliver safety information to the public. The flood safety training module is provided by the APM headquarters. This module is used as a reference by the ALPHA to train volunteers and APM staff who undergo training at ALPHA. The module describes the safety measures in dealing with a flood situation in a well-planned manner. In addition, this module briefly explains the actions the civilians should take and the role of APM in a flood disaster. The flood safety training module is divided into three flood situations namely before, during and after the flood. The module aims to provide a complete guideline on the measures that should be taken to avoid loss of life and property.

\section{B. Result Literature Review}

The result of the literature review method is the selected element of serious game for training and theory of psychology readiness.

1) Element of serious game: Total of 24 previous studies on serious games for training have been analyzed. From the 24 studies, there are four domains involved, namely natural disasters, medical, safety, and education. Seven studies in the domain of natural disasters, eight studies in the medical domain, six studies in safety domains and three studies in the education domain were done, giving a total of 24 studies. From the analysis of the 24 studies, a total of 26 serious game elements for training were identified. Elements of serious game for training as listed in Table I.

The elements obtained were analyzed to identify the appropriate elements for the game to be developed in this serious game. For objective purpose, there must be elements of the game that can enhance the intrinsic motivation of the players in order to attract players to continue playing.
TABLE I. ELEMENT OF SERIOUS GAME FOR TRAINING

\begin{tabular}{|c|c|c|c|c|c|c|}
\hline Bil & $\begin{array}{l}\text { Element / } \\
\text { Domain }\end{array}$ & Disaster & Medical & Safety & Education & Total \\
\hline 1 & Scenarios & 7 & 6 & 4 & 0 & 17 \\
\hline 2 & Interactive & 5 & 4 & 5 & 2 & 16 \\
\hline 3 & Immersive & 5 & 5 & 5 & 0 & 15 \\
\hline 4 & Goal & 3 & 6 & 4 & 1 & 14 \\
\hline 5 & Feedback & 2 & 6 & 3 & 2 & 13 \\
\hline 6 & Challenges & 4 & 3 & 1 & 3 & 11 \\
\hline 7 & Rules & 4 & 3 & 2 & 0 & 9 \\
\hline 8 & Involvement & 4 & 2 & 3 & 0 & 9 \\
\hline 9 & Storyline & 2 & 1 & 2 & 1 & 6 \\
\hline 10 & Reward & 1 & 2 & 0 & 1 & 4 \\
\hline 11 & $\begin{array}{l}\text { Players } \\
\text { objective }\end{array}$ & 2 & 0 & 2 & 0 & 4 \\
\hline 12 & $\begin{array}{l}\text { Game } \\
\text { Outcome }\end{array}$ & 1 & 0 & 2 & 0 & 3 \\
\hline 13 & Enjoyment & 1 & 0 & 1 & 0 & 2 \\
\hline 14 & $\begin{array}{l}\text { Game } \\
\text { mechanics }\end{array}$ & 0 & 0 & 2 & 0 & 2 \\
\hline 15 & Probability & 1 & 0 & 1 & 0 & 2 \\
\hline 16 & $\begin{array}{l}\text { Game } \\
\text { Procedures }\end{array}$ & 1 & 0 & 0 & 0 & 1 \\
\hline 17 & Resources & 1 & 0 & 0 & 0 & 1 \\
\hline 18 & Conflict & 1 & 0 & 0 & 0 & 1 \\
\hline 19 & Boundary & 1 & 0 & 0 & 0 & 1 \\
\hline 20 & Game Play & 1 & 1 & 0 & 0 & 1 \\
\hline 21 & $\begin{array}{l}\text { Interaction } \\
\text { Modes }\end{array}$ & 0 & 1 & 0 & 0 & 1 \\
\hline 22 & Frame story & 0 & 1 & 0 & 0 & 1 \\
\hline 23 & $\begin{array}{l}\text { Focus } \\
\text { attention }\end{array}$ & 0 & 1 & 0 & 0 & 1 \\
\hline 24 & Playability & 0 & 1 & 0 & 0 & 1 \\
\hline 25 & $\begin{array}{l}\text { Game } \\
\text { fullness, }\end{array}$ & 0 & 1 & 0 & 0 & 1 \\
\hline 26 & $\begin{array}{l}\text { A sense of } \\
\text { control }\end{array}$ & 0 & 1 & 0 & 0 & 1 \\
\hline
\end{tabular}

According to [17], intrinsic motivation can encourage user engagement with games. When users engage with the game, they start to feel attracted and will continue to repeat the game until it can influence their behavior [18]. Hence, this serious game can give users an awareness of the importance of flood preparation training.

Based on the analysis, elements that were identified to provide intrinsic motivation to users are the elements of scenario, feedback, challenge, reward and enjoyment. Table II shows the elements that identified. 
TABLE II. ELEMENT SRIOUS GAME FOR FLOOD SAFETY TRAINING

\begin{tabular}{|l|l|l|l|l|l|l|}
\hline Bil & $\begin{array}{l}\text { Elemen / } \\
\text { Domain }\end{array}$ & Disaster & Medical & Safety & Education & Total \\
\hline 1 & Scenarios & 7 & 6 & 4 & 0 & 17 \\
\hline 2 & Feedback & 2 & 6 & 3 & 2 & 13 \\
\hline 3 & Challenges & 4 & 3 & 1 & 3 & 11 \\
\hline 4 & Reward & 1 & 2 & 0 & 1 & 4 \\
\hline 5 & Enjoyment & 1 & 0 & 1 & 0 & 2 \\
\hline
\end{tabular}

a) Scenarios

From analysis of the 24 studies, the usage of scenario element is the highest in serious games for training as it was used in 17 studies. From the 17 studies, seven studies were in the domain of natural disasters, six studies in the medical domain, and four studies in the safety domain. However, the scenario element in the education domain was not present. This shows the scenario element is important to describe the situation in a game [19]. All the 17 studies just use one senario. According to [8], by using scenario elements, game progressions can be seen from time to time through events that occur during a game play. In a serious game for flood safety training, there are three flood scenarios, namely before, during and after flood. With different training scenarios, it can create resilient trainers because they can respond to different situations [20]. The events that occur in these scenarios will explain the use of the elements of feedback, challenges, rewards and enjoyment.

\section{b) Feedback}

A total of 13 studies used feedback element, implying the element is widely used in serious games for training. From the 13 studies, two studies used feedback element in the domain of natural disasters while six studies used the element in medical domain. Meanwhile, three studies represented the safety domain and two studies represented the educational domain. From this analysis, it was found that the feedback element is important in a serious game for training since the frequency of its usage appeared in 13 studies. Nevertheless, this element is less used in the domain of natural disasters. According to [9] and [21], the role of the feedback element in serious games for training is important as it can give intrinsic motivation to players to continue playing. In a serious game for flood safety training, the use of feedback element is to show game feedbacks on actions taken by player.

\section{c) Challenges}

Element of challenge is also an element that is used often in studies of serious game for training. 11 out of 24 studies used the challenge element with four studies in the domain of natural disasters, three in the medical domain, one in the safety domain and three in the education domain. According to [22], playing a challenging game can meet the needs of intrinsic motivation of players in terms of efficiency and autonomy. Challenge, in this context, is defined as the challenge of how players make decision to take necessary actions. If the player erred in decision making, the action taken will result in them being unable to continue the game. Therefore, the element of challenge is important in serious games of flood safety training. This is to inform the player of the actions that should and should not be taken during floods.

\section{d) Reward}

Element of reward was found to be less used in serious games for training. Only 4 studies used this element with one study representing the domain of natural disasters, two representing the medical domain and one representing the education domain. However, there was no application of reward element in the safety domain. Although this element is less applied in previous serious games for training, but the reward element should be used in serious games to encourage user to continue playing. According to [23], to attract users to keep playing, users need to be rewarded to increase the intrinsic motivation of users.

\section{e) Enjoyment}

For element of enjoyment is the least used in serious games for training. Only two out of all 24 studies applied this element, with each one study in the domain of natural disasters and the domain of education. In the medical and safety domains, the enjoyment element was not used. Even though the enjoyment element is less applied in previous studies, this element needs to be applied to give users a fun time while playing. According to [24], an exciting game provides a platform for players to experience fun and can lead to increased intrinsic motivation. The enjoyment element can be applied through the use of music or sound effects that can enable users to have fun and enjoy the game until the end.

2) Psychology readiness: The study was adapted and modified from a study by [25] in relation to the community's preparedness from a psychological perspective related to flood disaster. This study emphasized on the community preparedness to cope with the disaster. From the perspective of psychology, psychology readiness regarding preparation is important in discussing the level of readiness [26]. Psychology readiness explains the need for internal and external interaction of human preparation. Psychology readiness are based on three theory, namely cognitive theory, affective theory and psychomotor theory. All these theories influence each other and produce human behavior towards something as it happens in the issue of human readiness for flood disaster.

\section{Combination Result of the Two Study Methods}

The results of the two study methods are combined to produce a model of serious game for flood safety training that can provide intrinsic motivation to the players. Results are shown in Table III.

TABLE III. RESULT FROM TWO RESEARCH METHOD OF THE STUDY

\begin{tabular}{|c|c|c|c|}
\hline \multirow[b]{2}{*}{$\begin{array}{l}\mathrm{N} \\
\mathrm{O}\end{array}$} & \multirow[b]{2}{*}{ Preliminary Study } & \multicolumn{2}{|c|}{ Literature review } \\
\hline & & $\begin{array}{l}\text { Element } \\
\text { Game }\end{array}$ & $\begin{array}{l}\text { Psychology } \\
\text { Readiness }\end{array}$ \\
\hline & $\begin{array}{l}\text { Awareness of flood training preparation } \\
\text { among civilians }\end{array}$ & Scenario & $\begin{array}{l}\text { Cognitive } \\
\text { Affective } \\
\text { Psychomotor }\end{array}$ \\
\hline & $\begin{array}{l}\text { Campaign Used for Flood Training } \\
\text { Preparation }\end{array}$ & $\begin{array}{l}\text { Feedback } \\
\text { Challenge }\end{array}$ & Cognitive \\
\hline 3 & $\begin{array}{l}\text { Existing Method of Dissemination of } \\
\text { Flood Awareness Information }\end{array}$ & $\begin{array}{l}\text { Reward } \\
\text { Enjoyment }\end{array}$ & Affective \\
\hline 4 & $\begin{array}{l}\text { Technology Requirements for Flood } \\
\text { Awareness Training Preparation }\end{array}$ & $\begin{array}{l}\text { Game } \\
\text { Features }\end{array}$ & Psychomotor \\
\hline
\end{tabular}


1) Awareness of flood training preparation among civilians (Scenario): Since the level of awareness among the civilians about the importance of preparing for flood is still low, flood preparedness exercises in terms of physical and emotional aspects needs to be given to them. To make this training more effective, a technology is required to help the APM convey safety information to the civilians so that they can raise their awareness. Therefore, it is proposed that a serious game is the technology that can help the APM convey information about flood safety. The proposed serious game can provide awareness to the civilians of the importance of preparing for flood situations. For that purpose, the serious game must have a scenario element that can describe the actual flood situation. This game has to be developed based on the APM flood training module. Using the module, a simple storyline is built. There are three flood scenarios in this serious game: before flood, during flood and after flood. The sequence of scenarios is in the order of actual flood events. Each scenario has different training activities and focuses on important tasks in training. Besides that, cognitive theory, affective theory, and psychomotor theory are applied in scenario elements to illustrate the decision, feeling and action of the players when floods occur.

2) Campaign used for flood training preparation (feedback and challenge): The APM has organized campaigns in areas affected by flood disasters. However, all the campaigns are still less effective to civilians because they do not seem to have awareness in preparing for the flood disaster. Using serious game, information can be delivered more attractively and effectively. The use of feedback elements can deliver information directly to players in a style that can attract players to know the information they want to convey. When a player takes an action in the game, they will get a feedback from the game about the actions taken. Through this feedback, players will be given information related to floods. Additionally, the challenge element is also important to help the civilians to make decisions during emergencies. Through the use of challenge element, players can be more aware of their actions in whether the actions are right or wrong in a flood situation. Cognitive theory are applied in feedback and challenge element when players must make decisions.

3) Existing method of dissemination of flood awareness information (reward and enjoyment): The existing method needs to be upgraded using an effective technology so that it can stimulate the minds of the civilians to better understand the information delivered by APM. The existing medium to disseminate information is less effective because it does not attract interest of civilians. The use of serious game can attract the interest of the civilians. The use of reward and enjoyment elements can motivate players to continue playing the game. The affective theory is applied in reward and enjoyment element when the player feels happy to get marks.

4) Technology requirements for flood awareness training preparation (game features): Based on the suggestions on game features that APM has provided, a serious game with a role play game feature will be developed. Role play game is a computer game in which the players assume the roles of characters or take control of an avatar in a fictional setting. According to [27] role-playing games (RPGs) are digital games that strongly emphasize narrative, alternating action with episodes of exploration and dialogue, and with intricate reward mechanisms.

Among the game components available in this game is a scoring system to reward players [28] and using a pop-up box to give directions and information to players. Besides that, players can print out important information about flood safety. The game's user interface is also interesting and easy to understand as it displays a background illustrating the situation of the flood. The serious game also contains interactive multimedia elements as requested by the APM such as text, graphics, animation, and audio. Psychomotor theory can be seen throughout the game process.

Overall, the acquired elements were matched with the preliminary study result and were used for designing the game model. The description of the elements chosen for the game model is explained in the next sub-topic, which is the design model.

\section{MODEL DESIGN}

Five game elements are applied in this game of scenario, feedback, challenge, reward, and enjoyment. Other than element of serious game, psychology readiness theory is also involved in developing this serious game for preparation in terms of player emotion which is cognitive theory, affective theory and psychomotor theory. Each of the element of serious game and psychology readiness which is used elaborated further through the design of the model in Fig. 2.

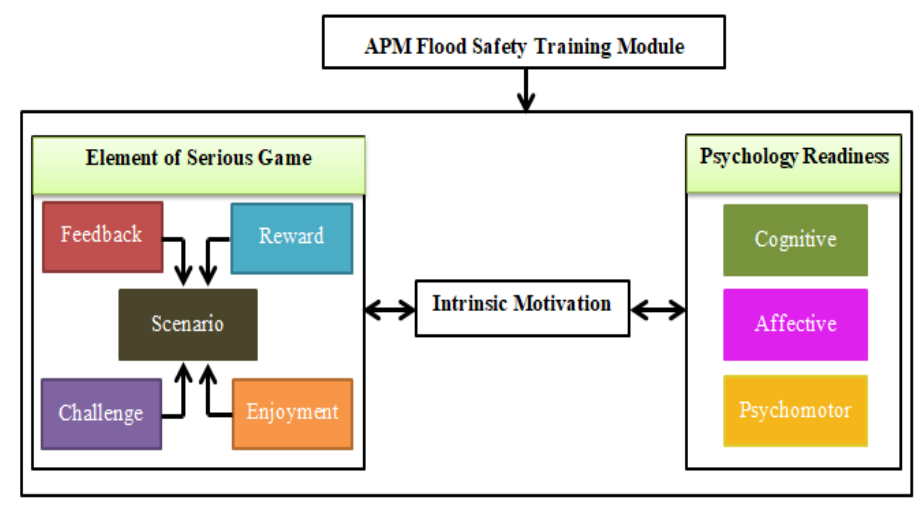

Fig. 2. Serious Game Model for Flood Safety Training.

\section{A. Game Element}

1) Scenario: The Scenario in a game is defined as the "context" in which the game takes place [29], the desired game development over time, and some events that occur when playing the game to improve the training. The general characteristic of a scenario is to describe the chronology of events. Each scenario has the goal of providing a lesson to the player. According to, scenarios in serious games must involve experts and follow the predetermined content of the study 
domain so that the objective of the game can be conveyed to players. Therefore, in this serious game, there are three scenarios describe the situation of the flood: scenario before flood, scenario during flood and scenario after flood. The three scenarios are designed based on the module derived from the ALPHA authority as a study reference.

2) Feedback: Feedback is the information received by the player base on the action taken [30]. Feedback occurs when a player performs a task [31]. Through the feedback received, the player can find out whether the action taken is correct or wrong. Furthermore, through the feedback received, the user can assess whether the task can be solved successfully or not [21]. According to [32], feedback is necessary to create interactions between the players and the game. Therefore, players need to understand the characteristics of a game, so that players can understand how the game gives feedback. Feedbacks can be provided in the form of visual and audio.

This game uses a type of visual feedback known as explanatory feedback. This feedback is also known as corrective feedback. According to [27], corrective feedback allows players to get information from the game about their game performance in terms of whether the action they took is right or wrong. In other words, this feedback only tells the user whether the action was taken correctly or wrongly. But explanatory feedback occurs when players take action in the game and receive feedback that clearly explains their performance quality. Explanatory feedback will show the answers by explaining why the answer is correct or wrong [33].

In the serious game for flood safety training, explanatory feedback is selected to give an explanation to the player in a visual form regarding the actions taken by the player either correct or incorrect when in a flood situation.

3) Challenges: Challenge is a task in a game that gives players a problem to continue the game [34]. A challenge occurs when a problem arises, the player can plan and choose different strategies to solve the problem. Each player has different abilities to solve problems in each game. Challenges in a game will test the player's skill level to make a choice. Challenges in every game are important to make the game more interesting. Additionally, this element makes the player not bored and not to give up easily. In this game, the challenge element in decision making is applied to allow the player to decide on the correct action that should be taken during an emergency. According to [35] [36]decision making is an important challenge in any game because it's difficult to predict how a person will react in an emergency crisis due to many factors involved in decision making.

4) Reward: The reward is a game element that gives users a sense of satisfaction and encourages them to continue playing to achieve more rewards [37]. According to [38], to attract the players to continue playing, players need to be rewarded. This incentive aims to increase the intrinsic motivation of players to keep playing. In this game model, rewards are given in the form of scores when players can complete each given task properly.
5) Enjoyment: The primary emotion of playing a game is enjoyment [39]. Enjoyment can be classified as an attitude towards experiences in entertainment, complete with cognitive and affective psychology [40]. The element of enjoyment is an important component that keeps players entertained while playing games. Without the enjoyment element in games, players can easily feel bored [24] and will be less interested in continuing the game. Interesting games provide platforms for players to experience fun and can lead to an increase in intrinsic motivation. Therefore, it is the responsibility of game designers to develop games that can give players a sense of enjoyment [39]. In order to make a game more enjoyable, there should be new additions to the game [38].

In this serious game, the element of enjoyment is highlighted in every flood scenario. The transition from one scenario to another with the addition of new things allows players to enjoy more and keep playing the game. Not only that, the enjoyment element is applied in this game through audio. Appropriate background music and sound effects will be applied in this game. For example, if a player scores well, a happy sound effect that can raise the player's spirits to keep playing will be played.

\section{B. Psychology Readiness}

1) Cognitive theory: Cognitive theory involves an individual's mental readiness to understand, think and reason [41] (make judgments and evaluations using intellect or logic) in any situation. When in an emergency, an individual's cognitive performance will be disturbed. The individual will make an unreasonable decision, and consequently the opportunity to live diminishes.

In the serious game for flood safety training, cognitive theory is highlighted when players face challenges to make decisions. For example in the scenario after the floods, the player enters the toilet to check the condition but there is a venomous animal (snake). In this instance, the player uses his cognitive ability to make the right decision and does not endanger himself. The player needs to decide whether to catch the snake himself or to contact 999. If the player decides to catch the snake himself, the player will die of a snake bite (game ends). Conversely, if a player calls 999, APM members will arrive to capture the snake and the player will score. In this situation, the player needs to think carefully to make the right decision because the decision made will influence the decision of the game.

2) Affective theory: Affective theory involves feelings [39][42]. This condition can be formed in a flood victim when faced with floods. In a serious game of flood safety training, there are two feelings of a player that show affective theory which are the feelings of fear and joy. Fear comes in the scenario of during floods wherein the players are on the way to the relief center and face anxiety when flood water starts to rise dramatically. In this situation, players are anxious to ask for help. The second scene is a venomous animal scene in a scenario of after floods. The affective theory in both scenes is highlighted through the use of sound effects. The sound 
effects used can make the player feel the anxiety. With this method, the game becomes more interesting. On the other hand, a happy feeling happens when players get scores. The affective theory of happy feeling is shown using a sound effect that indicates the increase of scores. This can give players a sense of excitement and make them more eager to continue the game.

3) Psychomotor theory: Psychomotor theory is the potential of physical maturity or preparation and cooperation to carry out a work. Psychomotor theory is described through physical action taken by players based on cognitive and affective theories. High psychomotor preparation enables an individual to act efficiently and effectively. This psychomotor theory can be seen throughout the game process. As long as the user plays the game, the player performs training and preparations for the flood.

\section{Intrinsic Motivation}

According to [43], human motivation refers to one's inspiration to act. Therefore, users need to be motivated to play a game to allow them to act according to the requirements of the game. One of the motivations that show a user really enjoys the game is intrinsic motivation [38]. Intrinsic motivation exists in individuals when doing activities [40] that can provide satisfaction to themselves and meet individual psychological needs naturally. In addition, according to [44], intrinsic motivation is present when the user strives to pursue the game because the game is interesting and fun. Digital games can give intrinsic motivation to players to continue playing [17] because these games can give them an excitement feeling. When players have intrinsic motivation, it makes them feel more positive to continue playing in the present time and in the future [17][45].

\section{DISCUSSION}

The preliminary study method is used to identify the problem and the domain needs. While literature review is used to identify problem regarding preview serious game in training and identify a solution. Based on the result of both methods, it used to design serious game for flood safety training.

Based on preliminary study result, flood preparation is important to determine the civilians' ability to experience in this situation. But the civilians are still unaware of the need to prepare for flood crisis. In the era of rapidly developing technology, people are more likely to receive information and conduct training in the form of interactive technology to enable them to interact with the technology. Because of that APM need a new technology which can attract civilians to do a preparation.

A serious game can be useful as a training tool for people who have to act in emergencies [46][47]. Therefore, preparations in the form of safety training using serious game were developed to train the civilians so that they will know the necessary measures that must be taken if floods occur. Serious games in training are could contribute to discipline human behaviors. The innovation of these serious games brings motivations, encourages good moral values and natures positive responses about flood preparation. It also can provide players with experience and making them enjoyable in a safe and reasonable situation these enable them to gain the knowledge, skills, and competencies that can be applied to life [48].

Based on literature review result serious game for flood safety training needs to develop more than one scenario in such a way can generate feedbacks more often. Furthermore serious games with other element such as challenges, reward, enjoyment making the serious game more interesting, and challenging tasks or quest, can influence the user experience of players and encourage them to further explore the game.

Other than preparation in physical training, emotional preparations should also be applied. Therefore, a serious game for flood safety training is carried out physically and emotionally. Through physical exercises, the emotions of civilians can be trained at the same time [49]. Emotions are related to an individual's psychology and mood that can be shown in physical behavior.

\section{CONCLUSIONS AND FUTURE WORKS}

In conclusion, to attract civilians to do preparation training, it requires an interactive approach. Therefore serious games have great potential to be used for training. Serious games aim to improve training processes by providing attractive, motivating and effective tools that may also create positive situations among trainer and civilians. Training activities utilizing serious games in 3D animation environments are used increasingly to create training scenarios.

The use of more than one scenario to allow trainees to learn techniques for various stressors which can help build awareness. This study focuses on the design of a serious game model for flood safety training that can be useful as a training tool for people who have to act in emergencies. The design model includes the elements of a serious game that have been identified and adapted to readiness psychology and will be used to develop a serious game based on the flood training modules set by the Civil Defence Force of Malaysia (APM). This makes the serious game to be more attractive and can give intrinsic motivation to players to keep playing. Limitation of this study focuses on element game for training only, not the overall element in the serious game. Besides that the content of flood management is from Malaysia only. For future studies, every single element serious game and theory of psychology readiness in the model developed in this study will be validated with the expert game and expert psychology using Inter-Rater Reliability method.

\section{ACKNOWLEDGMENT}

Thank you to the Faculty of Information Science and Technology, Universiti Kebangsaan Malaysia (UKM), Civil Defence Force (APM) and MyBrain15 Scheme under Ministry of Higher Education of Malaysia.

\section{REFERENCES}

[1] J. Ecalle, A. Magnan, and U. L. Lyon, "Serious games as new educational tools: How effective are they? A meta-analysis of recent studies," J. Comput. Assist. Learn., no. June, 2013.

[2] N. A. M. Zin and W. S. Yue, "History educational games design," Proc. 2009 Int. Conf. Electr. Eng. Informatics, ICEEI 2009, vol. 1, no. July, pp. 269-275, 2009. 
[3] S. Raihan, Z. Abidin, S. Fadzilah, M. Noor, and N. S. Ashaari, "Guidelines of Brain-based Learning through Serious Game for Slow Reader Students," 978-1-5386-0475-5/17/\$31.00 @2017 IEEE, 2017.

[4] N. A. M. Zin and W. S. Yue, "History educational games design," Proc. 2009 Int. Conf. Electr. Eng. Informatics, ICEEI 2009, vol. 1, no. July, pp. 269-275, 2009.

[5] V. Anindhita and D. P. Lestari, "Designing Interaction for Deaf Youths by Using User-centered Design Approach," 2016.

[6] E. A. A. R. Asiah Sarji, Fahmi Mahamood, Hirwan Jasbir, Norrafidah, "Musibah banjir. menghadapinya gaya perlis," Procedia Semin. R. Inst., no. SIRaj II, pp. 1-11, 2014.

[7] D. Sutherland and R. Dennick, "Exploring culture, language and the perception of the nature of science," Int. J. Sci. Educ., vol. 24, no. 1, pp. $1-25,2002$.

[8] A. J. Q. Tan, C. C. S. Lee, P. Y. Lin, S. Cooper, L. S. T. Lau, W. L. Chua, and S. Y. Liaw, "Designing and evaluating the effectiveness of a serious game for safe administration of blood transfusion: A randomized controlled trial," Nurse Educ. Today, vol. 55, no. April, pp. 38-44, 2017.

[9] C. Burgers, A. Eden, M. D. Van Engelenburg, and S. Buningh, "Computers in Human Behavior How feedback boosts motivation and play in a brain-training game," Comput. Human Behav., vol. 48, pp. 94103, 2015

[10] S. Luz, M. Masoodian, R. R. Cesario, and M. Cesario, "Using a serious game to promote community-based awareness and prevention of neglected tropical diseases," Entertain. Comput., vol. 15, pp. 43-55, 2016.

[11] G. Rebolledo-Mendez, K. Avramides, S. de Freitas, and K. Memarzia, "Societal impact of a serious game on raising public awareness," Proc. 2009 ACM SIGGRAPH Symp. Video Games - Sandbox '09, p. 15, 2009.

[12] J. Tixier, A. Dandrieux, and P. Slangen, "Training decision-makers : Existing strategies for natural and technological crisis management and specifications of an improved simulation-based tool," Saf. Sci., 2016.

[13] N. Mokhtar, A. Ismail, and Z. Muda, "Preliminary Study : Flood Awareness Training Preparation Using Serious Games," Asia-Pacific J. Inf. Technol. Multimed. J. Teknol. Mklm. dan Multimed. Asia-Pasifik Vol. 7 No. 2-2, December 201813 - 26 e-ISSN 2289-2192, vol. 7, no. 2, pp. 13-26, 2018.

[14] Ng, K. H., Bakri, A. and Abdul Rahman, A., Effects of persuasive designed courseware on children with learning difficulties in learning Malay language subject, Journal Of Information Systems Research And Innovation 2015, 56-65. doi:10.1007/s10639-015-9391-7.

[15] W. Bandara, S. Miskon, and E. Fielt, "A Systematic, Tool-Supported Method For Conducting Literature Reviews In Information Systems," in European Conference on Information Systems (ECIS), 2011, p. 221.

[16] C. Wohlin, "Guidelines for Snowballing in Systematic Literature Studies and a Replication in Software Engineering," Proc. 18th Int. Conf. Eval. Assess. Softw. Eng. 1-10., 2014.

[17] R. M. Ryan, C. S. Rigby, and A. Przybylski, "The motivational pull of video games: A self-determination theory approach," Motiv. Emot., vol. 30, no. 4, pp. 347-363, 2006.

[18] E. Uhlmann and J. Swanson, "Exposure to violent video games increases automatic aggressiveness," J. Adolesc., vol. 27, no. 1, pp. 41$52,2004$.

[19] E. Prasolova-førland, M. Fominykh, and A. I. Mørch, "Training Cultural Awareness in Military Operations in a Virtual Afghan Village: A Methodology for Scenario Development," 2013 46th Hawaii Int. Conf. Syst. Sci. Train., pp. 903-912, 2013.

[20] B. Kolen, B. Thonus, K. M. Zuilekom, and E. De Romph, "Evacuation a serious game for preparation," 2011 Int. Conf. Networking, Sens. Control. ICNSC 2011, no. April, pp. 317-322, 2011.

[21] P.-H. Tan, S. Ling, and C. Ting, "Adaptive digital game-based learning framework," DIMEA '07 Proc. 2nd Int. Conf. Digit. Interact. media Entertain. arts, no. 1, pp. 142-146, 2007.

[22] A. K. Przybylski, R. M. Ryan, and C. S. Rigby, "The motivating role of violence in video games," Personal. Soc. Psychol. Bull., vol. 35, no. 2, pp. 243-259, 2009
[23] M. V Birk, R. L. Mandryk, and C. Atkins, "The Motivational Push of Games: The Interplay of Intrinsic Motivation and External Rewards in Games for Training," CHI Play '16, Oct. 16-19, 2016, Austin, TX, USA (C) 2016 ACM. ISBN $978-1-4503-4456-2 / 16 / 10 \ldots \$ 15.00$ DOI http//dx.doi.org/10.1145/2967934.2968091, 2016.

[24] B. Kang and S. H. Tan, "Interactive Games: Intrinsic and Extrinsic Motivation, Achievement, and Satisfaction,” J. Manag. Strateg., vol. 5, no. 4, pp. 110-116, 2014.

[25] T. Pah and R. Syed, "Kesediaan diri anggota masyarakat daripada perspektif psikologi berkaitan bencana banjir di daerah segamat," J. techno Soc. issue Soc. Gov., vol. 7, no. No 2, pp. 1-24, 2015.

[26] J. C. Turner and P. J. Oakes, "The significance of the social identity concept for social psychology with reference to individualism, interactionism and social influence," Br. J. Soc. Psychol., vol. 25, no. 3, pp. 237-252, 1986.

[27] F. Cornillie, G. Clarebout, and P. Desmet, "The role of feedback in foreign language learning through digital role playing games," Procedia - Soc. Behav. Sci., vol. 34, pp. 49-53, 2012.

[28] H. Wang, "Game Reward Systems : Gaming Experiences and Social Meanings," Proc. DiGRA 2011 Conf. Think Des. Play., no. March, 2016.

[29] C. Hartog, "Scenario design for serious gaming," no. January, 2009.

[30] G. S. Alder, "Examining the relationship between feedback and performance in a monitored environment: A clarification and extension of feedback intervention theory," J. High Technol. Manag. Res. 17 157174 Examining, vol. 17, pp. 157-174, 2007.

[31] S. R. Serge, H. A. Priest, P. J. Durlach, and C. I. Johnson, "The effects of static and adaptive performance feedback in game-based training," Comput. Human Behav., vol. 29, no. 3, pp. 1150-1158, 2013.

[32] M. Schmierbach, Q. Xu, A. Oeldorf-Hirsch, and F. E. Dardis, "Electronic Friend or Virtual Foe: Exploring the Role of Competitive and Cooperative Multiplayer Video Game Modes in Fostering Enjoyment," Media Psychol., vol. 15, no. 3, pp. 356-371, 2012.

[33] C. I. Johnson, S. K. T. Bailey, and W. L. Van Buskirk, "Designing Effective Feedback Messages in Serious Games and Simulations: A in Serious Games and Simulations: A Research Review," Springer Int. Publ. Switz. 2017, no. September, 2017.

[34] T. G. Toolkit, “Game Elements," pp. 1-16, 2010.

[35] R. C. Allen, "Discovery of an embodying self: Cancer, identities, narratives.," Diss. Abstr. Int. Sect. B Sci. Eng., vol. 56, no. 9-B, p. 5192, 1996.

[36] N. El Mawas, J. Cahier, and I. C. D. Tech-cico, "Co-designing a serious game to train Emergency Medical Services," 978-1-4673-64041/13/\$31.00 @2013 IEEE, pp. 588-593, 2013.

[37] S. H. Hsu, J.-W. Chang, and C.-C. Lee, "Designing Attractive Gamification Features for Collaborative Storytelling Websites," Cyberpsychology, Behav. Soc. Netw., vol. 16, no. 6, pp. 428-435, 2013.

[38] M. V Birk, R. L. Mandryk, and C. Atkins, "The Motivational Push of Games: The Interplay of Intrinsic Motivation and External Rewards in Games for Training," CHI Play '16, Oct. 16-19, 2016, Austin, TX, USA (C) 2016 ACM. ISBN 978-1-4503-4456-2/16/10_.\$15.00 DOI http//dx.doi.org/10.1145/2967934.2968091, 2016.

[39] E. Boyle, T. M. Connolly, and T. Hainey, "The role of psychology in understanding the impact of computer games," Entertain. Comput., vol. 2, no. 2, pp. 69-74, 2011.

[40] R. L. Nabi and M. Krcmar, "Conceptualizing media enjoyment as attitude: Implications for mass media effects research," Commun. Theory, vol. 14, no. 4, pp. 288-310, 2004.

[41] S. J. Robinson and S. J. Robinson, "ScienceDirect ScienceDirect ScienceDirect How can Psychology inform disaster research? How can Psychology inform disaster research?," Procedia Eng., vol. 212, pp. 1083-1090, 2018.

[42] D. Öztürk, N. Çal, Z. Gocmen, A. Karada, and H. Karabulut, "Nurse Education Today Determining the effect of periodic training on the basic psychomotor skills of nursing students," 2014 Elsevier Ltd. All rights Reserv., vol. 35, pp. 402-407, 2015. 
[43] R. M. Ryan and E. L. Deci, "Intrinsic and Extrinsic Motivations: Classic Definitions and New Directions," Contemp. Educ. Psychol. 25, 54-67, vol. 67, pp. 54-67, 2000.

[44] E. D. Mekler, F. Brühlmann, A. N. Tuch, and K. Opwis, "Computers in Human Behavior Towards understanding the effects of individual gami fi cation elements on intrinsic motivation and performance," Comput. Human Behav., 2015.

[45] R. Tamborini, N. D. Bowman, A. Eden, M. Grizzard, and A. Organ, "Defining Media Enjoyment as the Satisfaction of Intrinsic Needs," J. Commun., vol. 60, no. 4, pp. 758-777, 2010.

[46] C. McGregor, B. Bonnis, B. Stanfield, and M. Stanfield, “A Method for Real-Time Stimulation and Response Monitoring Using Big Data and Its
Application to Tactical Training," 2015 IEEE 28th Int. Symp. Comput. Med. Syst., pp. 169-170, 2015.

[47] J. Tixier, A. Dandrieux, and P. Slangen, "Training decision-makers : Existing strategies for natural and technological crisis management and specifications of an improved simulation-based tool," Saf. Sci., 2016.

[48] T. S. M. T. W. \& N. A. H. M. Z. Hairul Fahmi Md. Muslim, "Kajian awal permainan serius untuk warga emas mengidap diabetes," Proceeding Glob. Summit Educ. GSE 2014 (E-ISBN 978-967-11768-56). 4-5 March 2014, Kuala Lumpur, MALAYSIA. Organ. by WorldConferences.net, vol. 2014, no. March, pp. 553-559, 2014.

[49] M. T. P. Adam, "A Serious Game Using Physiological Interfaces For Emotion Regulation Training In The Context Of Financial Decision-," Assoc. Inf. Syst. AIS Electron. Libr. ECIS 2012 Proc. Eur., 2012. 